\title{
Integration of Landsat TM and SPOT HRG Images for Vegetation Change Detection in the Brazilian Amazon
}

\author{
Dengsheng Lu, Mateus Batistella, and Emilio Moran \\ Dengsheng Lu and Emilio Moran are with the Center for the Study of Institutions, Population, and \\ Environmental Change (CIPEC) and the Anthropological Center for Training and Research on \\ Global Environmental Change (ACT), Indiana University, Bloomington, Indiana (dlu@indiana.edu) \\ Mateus Batistella is with the Brazilian Agricultural Research Corporation, EMBRAPA Satellite \\ Monitoring, Campinas, São Paulo, Brazil
}

\begin{abstract}
Traditional change detection approaches have been proven to be difficult in detecting vegetation changes in the moist tropical regions with multitemporal images. This paper explores the integration of Landsat Thematic Mapper (TM) and SPOT High Resolution Geometric (HRG) instrument data for vegetation change detection in the Brazilian Amazon. A principal component analysis was used to integrate TM and HRG panchromatic data. Vegetation change/non-change was detected with the image differencing approach based on the TM and HRG fused image and the corresponding TM image. A rule-based approach was used to classify the TM and HRG multispectral images into thematic maps with three coarse land-cover classes: forest, non-forest vegetation, and non-vegetation lands. A hybrid approach combining image differencing and post-classification comparison was used to detect vegetation change trajectories. This research indicates promising vegetation change techniques, especially for vegetation gain and loss, even if very limited reference data are available.
\end{abstract}

\section{Introduction}

The Brazilian Amazon has experienced high deforestation rates since the 1970s because of colonization projects initiated during that decade, associated road construction, and land-use change (Moran, 1981; Laurance et al., 2004). Over the Amazon basin, different stages of secondary succession and forest degradation are also part of the land-cover trajectories (Lucas et al., 2000; Roberts et al., 2002). Successional vegetation, with its rapid growth, may play an important role in the global carbon budget (Fearnside, 1996; Carreiras et al., 2006) and has significant ecological functions within the Amazonian ecosystems (Moran et al., 2000). Timely and accurate vegetation change detection in this region is valuable for reducing the uncertainty of carbon budgets and understanding the roles of vegetation in ecosystems.

Recently, the monitoring of forest degradation has also attracted increasing interest. Souza et al. (2003) used a decision tree classifier based on fraction images from the spectral mixture analysis of SPOT multispectral data to discriminate four forest types: intact forest, degraded forest, forest regeneration, and logged forest. The fraction images contain biophysical meanings, that is, they represent areal proportions of each endmember in a pixel. The change in forest structure reflects the change in the composition of such fractions in a pixel. In another study, Asner et al. (2004 and 2005) analyzed the impacts of selective logging on forest degradation with field measurements and spectral mixture analysis, and with the Carnegie Landsat Analysis System of Landsat ETM + images in moist tropical regions of the Brazilian Amazon. Normalized difference moisture index (NDMI) and tasseled cap wetness were also used to detect forest disturbance associated with forest type and harvest intensity (Franklin $e t$ al., 2002; Wilson and Sader, 2002; Jin and Sader, 2005). Because traditional pixel-based 
change detection approaches often generate the "salt-and-pepper" effect in the resultant image, Desclee et al. (2006) used an object-based approach to detect forest change and provided better change detection accuracy, but this approach cannot provide the change trajectories. Lambin (1999) discussed the methodological issues for monitoring forest degradation using remotesensing data and indicated that only the use of suitable biophysical variables could lead to accurate detection of forest degradation. These approaches require the collection of a large number of sample plots in the field, which is often difficult and time consuming, especially in the Amazon.

The monitoring of non-forest vegetation change in the moist tropical regions has not attracted sufficient attention yet. The non-forest vegetation may include different stages of successional vegetation, agroforestry, pastures, and perennial plantations (e.g., coffee, cocoa). Because of land-use intensification, the conversion or modification within the non-forest vegetation class is common. Although detection of loss or gain within the non-forest vegetation category is a challenge due to the similar spectral features, the small patch sizes, and the limitation of using high spatial resolution remotely sensed data for large regions, the information about non-forest vegetation change is important in reducing the uncertainty in carbon estimations.

Many change detection algorithms have been developed (Singh, 1989; Coppin et al., 2004; Lu et al., 2004a), but most of them, such as image differencing, principal component analysis (PCA), and ratioing, cannot provide detailed vegetation change trajectory information.

Although the post-classification comparison approach can indicate detailed land-cover change trajectories, the accuracy of the change detection result greatly depends on the accuracies of the classified images for both dates. In practice, a detailed vegetation classification with historically remotely sensed data is a challenge, especially in moist tropical regions due to the complex biophysical environments and the lack of local reference data that could be used as training samples during image classification (Foody et al., 1996; Roberts et al., 2002; Lu et al., 2004b).

Much previous research for change detection is based on images acquired by the same sensor. However, in moist tropical regions, the frequent cloud conditions often affect the acquisition of high-quality optical sensor data. Different sensor data provide more chances to acquire cloud-free images, but using different sensor data often makes it difficult to select a suitable change detection approach. Most approaches require that the image data be from one sensor with similar acquisition dates in different detection years so the impacts of vegetation phenology and different sensor responses can be minimized. Also, the collection of ground reference data, especially for historical remote-sensing data, in moist tropical regions of the Amazon is often challenging due to the difficult access to some remote areas. On the other hand, it is crucial to monitor vegetation change in such regions, as they play a key role in the global climate balance. Thus, it is important to develop a new approach for vegetation change detection based on the characteristics of different sensor data and limited reference data, so detailed vegetation change information can be extracted. In this article, we aim to develop a hybrid approach for detection of detailed vegetation change trajectories based on the use of Landsat Thematic Mapper (TM) and SPOT HRG (High Resolution Geometric) instrument data. Specifically, the integration of TM and HRG data was used for detection of vegetation change/non-change, and a hybrid approach combining image differencing and traditional postclassification comparison was then used for the development of more detailed vegetation change information.

\section{Study Area}

The State of Rondônia has experienced high deforestation rates over the last two decades. In fact, the deforestation rates in Rondônia ranged from 1.14 to 2.62 percent per year between 
1991 and 2000, much higher than the overall deforestation rate (ranging from 0.37 to 0.80 percent per year) in the Brazilian Amazon during the same period (INPE, 2002). Following the national strategy of regional occupation and development, colonization projects initiated by the Brazilian government in the 1970s played a major role in this process (Moran, 1981; Schmink and Wood, 1992). Most colonization projects in the State were designed to settle landless migrants. The immigrants have transformed the forested landscape into a mosaic of cultivated crops, pastures, different stages of successional vegetation, urbanized areas, and forest remnants.

The study area is located at Machadinho d'Oeste in northeastern Rondônia (Figure 1). It is a newer colonization initiative than areas along the Cuiabá-Porto Velho Highway. The settlement is adjacent to the borders with the states of Amazonas and Mato Grosso. A well-defined dry season lasts from June to August. The annual average precipitation is 2,016 mm and the annual average temperature is $25.5^{\circ} \mathrm{C}$ (Rondônia, 1998). The terrain is undulating, ranging from 100 to $450 \mathrm{~m}$ above sea level. Several soil types, mainly alfisols, oxisols, ultisols, and alluvial soils, have been identified (Bognola and Soares, 1999). Settlers, rubber tappers, and loggers inhabit the area, transforming the landscape through their economic activities and use of resources (Batistella, 2001). Farming systems are mainly household-based, and little depends on larger group efforts. Rubber tappers have rights over communal forest reserves where they practice extraction. Loggers play a major role in providing access to remote areas within the settlement and in starting the occupation process, as they open trails through the forest to reach valuable species.

\section{Methods}

Vegetation change detection is a complex procedure. Figure 2 illustrates the major steps, including image preprocessing (e.g., image-to-image registration, atmospheric calibration), image classification, post-classification comparison, data fusion, image differencing, and a hybrid approach for vegetation change detection.

\section{Image Collection and Preprocessing}

Two sensor data, Landsat-5 TM and SPOT-5 HRG images, were used in this research. The TM image with 30-meter spatial resolution has six bands, covering three visible bands (blue, green, and red), one near-infrared (NIR) band, and two shortwave infrared (SWIR) bands. The HRG image has five bands, covering one panchromatic band with 5-meter spatial resolution, two visible (green and red) bands, one NIR band with 10-meter spatial resolution, and one SWIR band with 20-meter spatial resolution. The TM image was acquired on 18 June 1998, with a sun elevation angle of $42^{\circ}$, and the HRG image was acquired on 26 June 2003 with a sun elevation angle of $51^{\circ}$.

Image registration and atmospheric calibration are two important aspects in the image preprocessing procedure. The importance of accurate registration of multitemporal images is obvious because spurious results of change detection would be produced if misregistration were to occur (Townshend et al., 1992; Dai and Khorram, 1998). An image-to-image registration between TM and HRG images was performed. The HRG image was used as a reference image, and the TM image was registered to the HRG image to the Universal Transverse Mercator coordinate system.

The nearest-neighbor algorithm was used to resample the TM image into pixel sizes of $10 \mathrm{~m}$ by $10 \mathrm{~m}$, in order to be consistent with HRG data and to make use of the rich spatial information inherent in the higher spatial resolution of HRG data during the TM and HRG data fusion procedure. The registration error of 0.1816 pixels ( $x$ error: $0.1409, y$ error: 0.1145 ) for the TM image was obtained during image registration. The 5 -meter $\mathrm{HRG}$ panchromatic image was also 
resampled to 10-meter spatial resolution. Thus, all HRG and TM data had the same pixel size of $10 \mathrm{~m} \times 10 \mathrm{~m}$.

Conversion of digital numbers to radiance or surface reflectance is a requirement for quantitative analyses of multitemporal images. Many methods ranging from simple relative calibration and dark object subtraction to complex models (e.g., 6S) have been developed for radiometric and atmospheric normalization or correction (Chavez, 1996; Vermote et al., 1997; Tokola et al., 1999; Song et al., 2001; Canty et al., 2004). The dark object subtraction approach is an image-based procedure that corrects for the effects caused by solar zenith angle, solar radiance, and atmospheric scattering (Chavez, 1996; Lu et al., 2002) and, hence, used in this paper for the atmospheric calibrations of TM and HRG images:

$$
\begin{aligned}
& R_{\lambda}=\mathrm{PI} * D *\left(L_{\lambda}-L_{\lambda . \text { haze }}\right) /\left(\text { Esun }_{\lambda} * \operatorname{COS}(\theta)\right), \\
& L_{\lambda}=D N_{\lambda} / A_{\lambda}, \text { for SPOT HRG data, and } \\
& L_{\lambda}=\text { gain }_{\lambda} * D N_{\lambda}+\text { bias }_{\lambda} \text { for Landsat TM data, }
\end{aligned}
$$

where $L_{\lambda}$ is the apparent at-satellite radiance for spectral band $\lambda, D N_{\lambda}$ is the digital number of spectral band $\lambda, A_{\lambda}$ is the calibration factor for spectral band $\lambda$ of the SPOT HRG image, $R_{\lambda}$ is the calibrated reflectance, $L_{\lambda . \text {.haze }}$ is path radiance, $E s n_{\lambda}$ is exo-atmospheric solar irradiance, $D$ is the distance between the Earth and Sun, and $\theta$ is the sun zenith angle. The path radiance for each band was identified based on the analysis of water bodies and shades in the images.

\section{Image Classification}

Much previous research has demonstrated that vegetation classification in the moist tropical regions is often difficult due to the complex stand structure, abundant tree species, and complex environmental conditions (Foody et al., 1996; Rignot et al., 1997; Santos et al., 2003; Vieira et al., 2003; Lu et al., 2004b). However, non-vegetated lands (e.g., bare soils, infrastructure, and water) have significantly different spectral signatures compared to vegetation types. Mature forests have different features that can be separated from non-forest vegetation (e.g., successional forests, agroforestry, perennial plantations, and pastures). Figure 3 illustrates the different spectral features of a TM image for distinct land-cover types. Water has very low reflectance values in NIR and SWIR bands, urban or bare soils have higher reflectance values than other classes in visible and SWIR bands, and mature forests have lower reflectance values than non-forest vegetation types in NIR and SWIR bands. The three land-cover classes (forest, non-forest vegetation, and non-vegetation lands) were classified with a rule-based approach (Figure 4). The normalized difference vegetation index [i.e., NDVI $=(\mathrm{NIR}-\mathrm{red}) /(\mathrm{NIR}+\mathrm{red})]$ image calculated from TM or HRG image was also used in image classification. The thresholds were determined from the sample plots. Approximately 10 to 15 sample plots covering water, urban, bare soils, mature forest, and non-forest vegetation classes were identified for both dates of TM and HRG multispectral images. A statistical analysis (minimum, maximum, mean, and standard deviation) for each class was conducted, and thresholds were determined based on the comprehensive analysis of multispectral signatures and NDVI images. Figure 5 illustrates the classified images from TM and HRG multispectral images. Comparison of the classified images from TM (1998) and HRG (2003) indicated that non-forest vegetation and nonvegetation (e.g., urban, bare soils) areas increased, consequently forested areas decreased.

In order to use the classified images for change detection with the post-classification comparison approach, it is important to make sure that the classified images have high classification accuracies, because the change detection accuracy depends on the accuracy of both classified images. Hence, a total of 200 sample plots were randomly allocated on the classified images. The land-cover type for each plot was examined on the HRG and TM color composites with visual interpretation. Three and five plots were found to be misclassified on 
the HRG and TM images, respectively. Thus, the overall classification accuracies of 98.5 percent and 97.5 percent for HRG and TM images, respectively, were obtained and these accuracies were satisfactory for the detection of land-cover changes.

\section{Vegetation Change Detection}

The post-classification comparison approach was used to detect the changes between forest, non-forest vegetation, and non-vegetation lands (see Table 1). However, because of the difficulty in classifying specific vegetation classes with remotely sensed data, the postclassification comparison approach cannot provide sufficient detailed vegetation change information, such as vegetation growth or degradation. Non-forest vegetation is a complex category, which may include the changes within and/or between successional vegetation, agroforestry, perennial plantations, and pastures. Such changes are difficult to detect, especially between successional vegetation stages and agroforestry because of the difficulty in separating them. Therefore, these changes were detected based on the image differencing approach.

Traditional change detection approaches require that the multitemporal images have the same spectral and spatial resolutions. Because of the different sensor data used in this research, the traditional approaches such as image differencing are not suitable for change/non-change detection. Hence, a data fusion based approach was used for vegetation change/non-change detection, based on the TM multispectral (1998) and HRG panchromatic (2003) images.

The steps used for change detection based on the PCA data fusion approach are summarized as follows:

1. Register the TM image to the same coordinate system as the HRG panchromatic image and resample both the TM multi-spectral and the HRG panchromatic images to the same pixel size of $10 \mathrm{~m} \times 10 \mathrm{~m}$;

2. Transform the TM six bands into six principal components (PCs) using the PCA approach;

3. Normalize the HRG panchromatic image to the PC1 image from the $1998 \mathrm{TM}$ multispectral image through a regression analysis of sample plots of pseudo-invariant objects (e.g., intact forest, cultivated pastures, bare soils);

4. Replace PC1 with normalized $H R G$ panchromatic image and create a new data file;

5. Conduct the inverse PCA approach to transform the new data file into a new six-band image, which incorporates the information from the HRG panchromatic image and meanwhile preserves the multispectral features in the TM image;

6. Conduct image differencing between the bands of integrated image and corresponding TM bands: $\operatorname{Diff}_{i}=B_{f i}-B_{t m i}$, where $B_{f i}$ is the band $i$ from the data fused image, and $B_{t m i}$ is the TM band $i$. TM band 5 was used because previous research indicated that this band provided the best change detection result in this study area (Lu et al., 2005).

7. Identify thresholds to develop the change/non-change image on the difference image based on pseudo-invariant objects. The histogram of unchanged pixels in a study area is normally distributed. In this study, the statistical analysis (minimum, maximum, mean, and standard deviation) of selected sample data of unchanged objects was conducted, and the thresholds were determined, based on the comprehensive analysis of statistical parameters (Lu et al., 2005). The selection of thresholds $[-t, t]$ is a critical step for detection of change/non-change information. The following rules were used to determine vegetation change status: gain, loss, or non-change. 
- When the pixel value in the difference image was within the thresholds [- $t$, $t$ ], this pixel was assigned 0 as non-change;

- When the pixel value in the difference image was greater than $t$, this pixel was assigned -1 as vegetation loss. Three possible changes in vegetation loss included forest to non-forest vegetation (NFV) or non-vegetation lands (NVL); NFV to NVL; and NFV to less mature NFV.

- When the pixel value in the difference image was less than $-t$, this pixel was assigned 1 as vegetation gain. Two possible changes in vegetation gain included bare soils to NFV (i.e., successional vegetation, agroforestry, perennial plantations, or pasture) and less mature vegetation cover (i.e., pasture, young agroforestry systems, or initial successional vegetation) to more mature agroforestry or successional vegetation.

The post-classification comparison approach provided the information about vegetation conversion, and the image differencing approach provided the vegetation gain or loss information. Thus, a hybrid approach, which is a combination of both approaches, can provide vegetation change detection information with details. For example, if a pixel was detected as unchanged forest based on the post-classification comparison approach, and the same pixel was detected as vegetation loss based on the image differencing approach, this pixel was assigned as forest degradation. Table 2 summarizes the potential vegetation change trajectories based on the analysis of vegetation conversion image and change/non-change detection image. Forest can be changed to non-forest vegetation or non-vegetation land due to complete deforestation. Forest can also be disturbed due to selective logging, or less dense forest can grow to denser forest due to natural growth. Non-forest vegetation can be disturbed to less mature vegetation or converted to non-vegetation lands. Non-vegetation lands can also be regenerated to non-forest vegetation.

\section{Results and Discussion}

The vegetation change information can be effectively extracted from the PCA data fused images which were generated for both dates. Figure 6 provides a comparison of images before and after data fusion. The numbers in Figure 6a show mature forest on TM band 5 image acquired in 1998, but the forest was cleared by 2003, as shown on the HRG panchromatic image of Figure 6b. After data fusion using the PCA approach, the deforested areas were highlighted with the appearance of different gray levels in the fused band 5 image, compared with unchanged mature forest in dark gray (Figure 6c). In the difference image based on the fused band 5 and the original TM band 5 (i.e., the difference between Figure $6 \mathrm{c}$ and $6 \mathrm{a}$ ), the deforested area was highlighted with bright gray or white, obviously different from unchanged areas (Figure 6d). Based on the thresholds identified from the pseudo-invariant objects (e.g., unchanged mature forest, bare soil, pastures) on the difference image, a final vegetation change/ non-change image was developed (Figure 7). The white areas in Figure 7 indicate vegetation loss due to deforestation or degradation, the black areas indicate vegetation gain due to regeneration or vegetation growth, and the gray areas indicate unchanged land covers. One unusual thing in the fused image (Figure 6c) and the change detection image (Figure 7) is that the river and some urban areas are highlighted. The error in water was caused by the significant differences of reflectance values between the HRG panchromatic image and the PC1 from TM multispectral data. The HRG panchromatic band covers the visible and near-infrared wavelengths. Water has higher reflectance than vegetations in the HRG panchromatic band (Figure 6b), while in near-infrared and shortwave infrared wavelengths (e.g., in the HRG SWIR band and in TM bands 4, 5, and 7) water has very low reflectance compared with vegetation or other non-vegetation lands (Figure 6a). The PC1 is a linear combination of six TM bands (e.g., $\mathrm{PC} 1=0.104 \mathrm{~b} 1+0.203 \mathrm{~b} 2+0.232 \mathrm{~b} 3+0.687 \mathrm{~b} 4+0.588 \mathrm{~b} 5+0.274 \mathrm{~b} 7)$, in which most of 
the information is from NIR and SWIR bands (TM bands 4 and 5). In both bands, water has very low reflectance compared with visible bands. Hence, water has lower values than other land covers in PC1. When PC1 was replaced with the HRG panchromatic image in the data fusion approach, water information was thus enhanced in the fused image (Figure 6c).

Amazonian small urban areas are complex environments, so mixed pixels are very common. Also, different sun elevation angles when the TM and HRG data were acquired influenced the shadows and the composition of reflectance from different components. Considering the different spatial resolutions between TM and HRG panchromatic data ( $30 \mathrm{~m}$ versus $5 \mathrm{~m}$ ), the influences of different sun elevation angles, and image registration errors, it is reasonable to expect some unusual appearances within the urban regions in the difference image. Because water and urban/bare soils were classified as a non-vegetation category in both images, the unusually enhanced information in the data fused image and change detection image was not affected in the final vegetation change detection results.

Compared with traditional change detection approaches, the hybrid approach can provide more detailed information about vegetation change trajectories, as illustrated in Figure 8. The postclassification comparison approach provides vegetation conversion information, including forest conversion, and non-forest vegetation conversion (see Figure 8a), while the hybrid approach provides such change information as forest degradation and non-forest vegetation loss or gain (see Figure $8 \mathrm{~b}$ ). Figure 8 indicates that the conversion from forest to non-forest vegetation or from non-forest vegetation to non-vegetation land accounts for most of the deforestation areas. Although no quantitative accuracy assessment for the change detection result was conducted due to the lack of reference data, visually comparing the change detection image with the color composite of both dates of SWIR images (i.e., assigned TM band 5 and HRG band 4 as red and green) indicated that this result is satisfactory, and the hybrid approach is promising for vegetation change detection with different sensor data.

Two categories of change detection techniques can be roughly grouped. One is used to detect binary change/non-change information, using such approaches as image differencing, image ratioing, vegetation index differencing, and PCA; the other approach is to detect detailed "fromto" change trajectory, using such approaches as the post-classification comparison (Lu et al., 2004a). The simple change/non-change information is not sufficient for most applications, however, detailed "from-to" change detection based on classification approaches require that both images were accurately classified. In practice, the complex landscapes and environmental conditions of the Amazon basin often result in poor land-cover classification accuracies, especially for classification of vegetation types. On the other hand, collecting a large number of field data is, in particular, costly and sometimes impractical in that region. Therefore, applications of historical remote-sensing data for land-cover classifications are often difficult because of lack of ground truth data that can be used as training samples. This problem often induces difficulty in detecting land-cover "from-to" change. Therefore, it is necessary to develop a method that does not require use of training sample data for the detailed land-cover classifications with the historical remote-sensing data. The hybrid approach described in this article meets this requirement and proved successful in vegetation change detection in this study. This approach has some advantages over traditional change detection approaches, as no training samples are required for detailed vegetation classification, detailed vegetation change trajectories can be developed, and no strict requirements for radiometric and atmospheric calibrations are required.

\section{Conclusions}

Traditional change detection approaches often require that the multitemporal images come from the same sensor data acquired during similar seasons, but in the moist tropical regions of 
the Amazon, acquisition of high-quality multitemporal images is often difficult, resulting in the difficulty in selection of suitable change detection approaches. The hybrid approach developed in this paper can be used for analyzing different sensor images for vegetation change detection. The PCA data fusion approach can effectively extract the vegetation change information, and the combination of image differencing and post-classification comparison can indicate the vegetation change trajectories. This approach is especially valuable when same sensor data and reference data are not available.

\section{Acknowledgments}

The authors wish to thank the U.S. National Science Foundation Biocomplexity in the Environment initiative (NSF SES008351), the National Aeronautics and Space Administration (Grant No. NCC5-695), and Brazil's Embrapa Satellite Monitoring for their support. This project is part of the Large Scale Biosphere-Atmosphere Experiment in Amazônia (LBA) Program, LC-09, which aims to examine the human and physical dimensions of land-use and landcover change in the region.

\section{References}

Asner GP, Keller M, Pereira R Jr, Zweede JC, Silva JNM. Canopy damage and recovery after selective logging in Amazonia: Field and satellite studies. Ecological Applications 2004;14:S280-S298.

Asner GP, Knapp DE, Broadbent EN, Oliveira PJC, Keller M, Silva JN. Selective logging in the Brazilian Amazon. Science 2005;310:480-482. [PubMed: 16239474]

Batistella, M. PhD dissertation. Indiana University, Bloomington; Indiana: 2001. Landscape Change and Land-use/Land-cover Dynamics in Rondônia, Brazilian Amazon; p. 399

Bognola, IA.; Soares, AF. Pesquisa em Andamento. Embrapa Monitoramento por Satélite; Campinas, Brazil: 1999. Solos das "glebas 01, 02, 03 e 06" do Município de Machadinho d'Oeste, RO; p. 7

Canty MJ, Nielsen AA, Schmidt M. Automatic radiometric normalization of multitemporal satellite imagery. Remote Sensing of Environment 2004;91:441-451.

Carreiras JMB, Pereira JMC, Campagnolo ML, Shimabukuro YE. Assessing the extent of agriculture/ pasture and secondary succession forest in the Brazilian Legal Amazon using SPOT VEGETATION data. Remote Sensing of Environment 2006;101:283-298.

Chavez PS Jr. Image-based atmospheric corrections-Revisited and improved. Photogrammetric Engineering \& Remote Sensing 1996;62(10):1025-1036.

Coppin P, Jonckheere I, Nackaerts K, Muys B, Lambin E. Digital change detection methods in ecosystem monitoring: A review. International Journal of Remote Sensing 2004;25:1565-1596.

Dai XL, Khorram S. The effects of image misregistration on the accuracy of remotely sensed change detection. IEEE Transactions on Geoscience and Remote Sensing 1998;36:1566-1577.

Desclee B, Bogaert P, Defourny P. Forest change detection by statistical object-based method. Remote Sensing of Environment 2006;102:1-11.

Fearnside PM. Amazonian deforestation and global warming: Carbon stocks in vegetation replacing Brazil's Amazon forest. Forest Ecology and Management 1996;80:21-34.

Foody GM, Palubinskas G, Lucas RM, Curran PJ, Honzák M. Identifying terrestrial carbon sinks: Classification of successional stages in regenerating tropical forest from Landsat TM data. Remote Sensing of Environment 1996;55:205-216.

Franklin SE, Lavigne MB, Wulder MA, McCaffrey TM. Large-area forest structure change detection: An example. Canadian Journal of Remote Sensing 2002;28:588-592.

Instituto Nacional de Pesquisas Espaciais (INPE). Monitoring of the Brazilian Amazon Forest by Satellite 2000-2001. INPE, São José dos Campos; SP, Brazil: 2002. p. 23

Jin S, Sader SA. Comparison of time series tasseled cap wetness and the normalized difference moisture index in detecting forest disturbances. Remote Sensing of Environment 2005;94:364-372.

Lambin EF. Monitoring forest degradation in tropical regions by remote sensing: Some methodological issues. Global Ecology and Biogeography 1999;8:191-198.

Laurance W, Albernaz AKM, Fearnside PM, Vasconcelos HL, Ferreira LV. Deforestation in Amazonia. Science 2004;304:1109. [PubMed: 15155931] 
Lu D, Mausel P, Brondízio E, Moran E. Assessment of atmospheric correction methods for Landsat TM data applicable to Amazon basin LBA research. International Journal of Remote Sensing 2002;23:2651-2671.

Lu D, Mausel P, Brondizio E, Moran E. Change detection techniques. International Journal of Remote Sensing 2004a;25:2365-2407.

Lu D, Mausel P, Batistella M, Moran E. Comparison of land-cover classification methods in the Brazilian Amazon basin. Photogrammetric Engineering \& Remote Sensing 2004b;70(7):723-731.

Lu D, Mausel P, Batistella M, Moran E. Land cover binary change detection methods for use in the moist tropical region of the Amazon: A comparative study. International Journal of Remote Sensing 2005;26:101-114.

Lucas RM, Honzák M, Curran PJ, Foody GM, Mline R, Brown T, Amaral S. The regeneration of tropical forests within the Legal Amazon. International Journal of Remote Sensing 2000;21:2855-2881.

Moran, EF. Developing the Amazon. Indiana University Press; Bloomington, Indiana: 1981.

Moran EF, Brondízio E, Tucker JM, da Silva-Forsberg MC, McCracken SD, Falesi I. Effects of soil fertility and land use on forest succession in Amazônia. Forest Ecology and Management 2000;139:93-108.

Rignot E, Salas WA, Skole DL. Mapping deforestation and secondary growth in Rondônia, Brazil, using imaging radar and Thematic Mapper data. Remote Sensing of Environment 1997;59:167-179.

Roberts DA, Numata I, Holmes K, Batista G, Krug T, Monteiro A, Powell B, Chadwick OA. Large area mapping of land-cover change in Rondonia using decision tree classifiers. Journal of Geophysical Research 2002;107(D20):8073 LBA 40-1-40-18.

Rondônia. Diagnóstico sócio-econômico do Estado de Rondônia e assistência técnica para formulação da segunda aproximação do zoneamento sócio-econômico-ecológico - Climatologia. Vol. 1. Governo de Rondônia/PLANAFLORO; Porto Velho, Brasil: 1998.

Santos JR, Freitas CC, Araujo LS, Dutra LV, Mura JC, Gama FF, Soler LS, Sant' Anna SJS. Airborne P-band SAR applied to the aboveground biomass studies in the Brazilian tropical rainforest. Remote Sensing of Environment 2003;87:482-493.

Singh A. Digital change detection techniques using remotely sensing data. International Journal of Remote Sensing 1989;10:989-1003.

Schmink, M.; Wood, CH. Contested Frontiers in Amazônia. Columbia University Press; New York: 1992. p. 387

Song C, Woodcock CE, Seto KC, Lenney MP, Macomber SA. Classification and change detection using Landsat TM data: When and how to correct atmospheric effect. Remote Sensing of Environment 2001;75:230-244.

Souza C Jr, Firestone L, Silva LM, Roberts D. Mapping forest degradation in the Eastern Amazon from SPOT 4 through spectral mixture models. Remote Sensing of Environment 2003;87:494-506.

Tokola T, Löfman S, Erkkilä A. Relative calibration of multitemporal Landsat data for forest cover change detection. Remote Sensing of Environment 1999;68:1-11.

Townshend JRG, Justice CO, Gurney C, McManus J. The effect of image misregistration on the detection of vegetation change. IEEE Transactions on Geoscience and Remote Sensing 1992;30:1054-1060.

Vermote E, Tanre D, Deuze JL, Herman M, Morcrette JJ. Second simulation of the satellite signal in the solar spectrum, 6S: An overview. IEEE Transactions on Geoscience and Remote Sensing 1997;35:675-686.

Vieira ICG, de Almeida AS, Davidson EA, Stone TA, de Carvalho CJR, Guerrero JB. Classifying successional forests using Landsat spectral properties and ecological characteristics in eastern Amazonia. Remote Sensing of Environment 2003;87:470-481.

Wilson EH, Sader SA. Detection of forest harvest type using multiple dates of Landsat TM imagery. Remote Sensing of Environment 2002;80:385-396. 


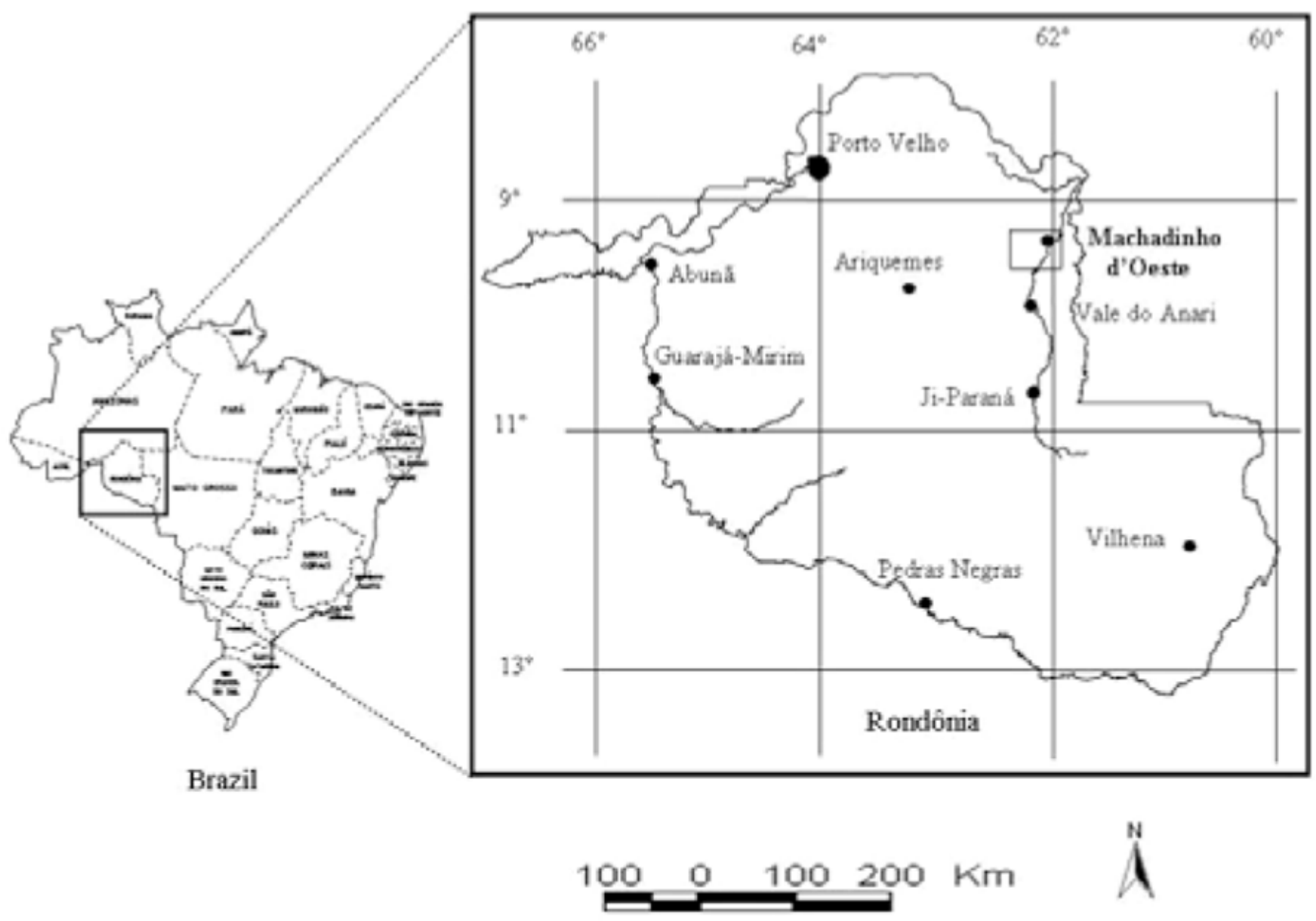

Figure 1.

Location of the study area: Machadinho d'Oeste in northeastern Rondônia State, Brazil. 


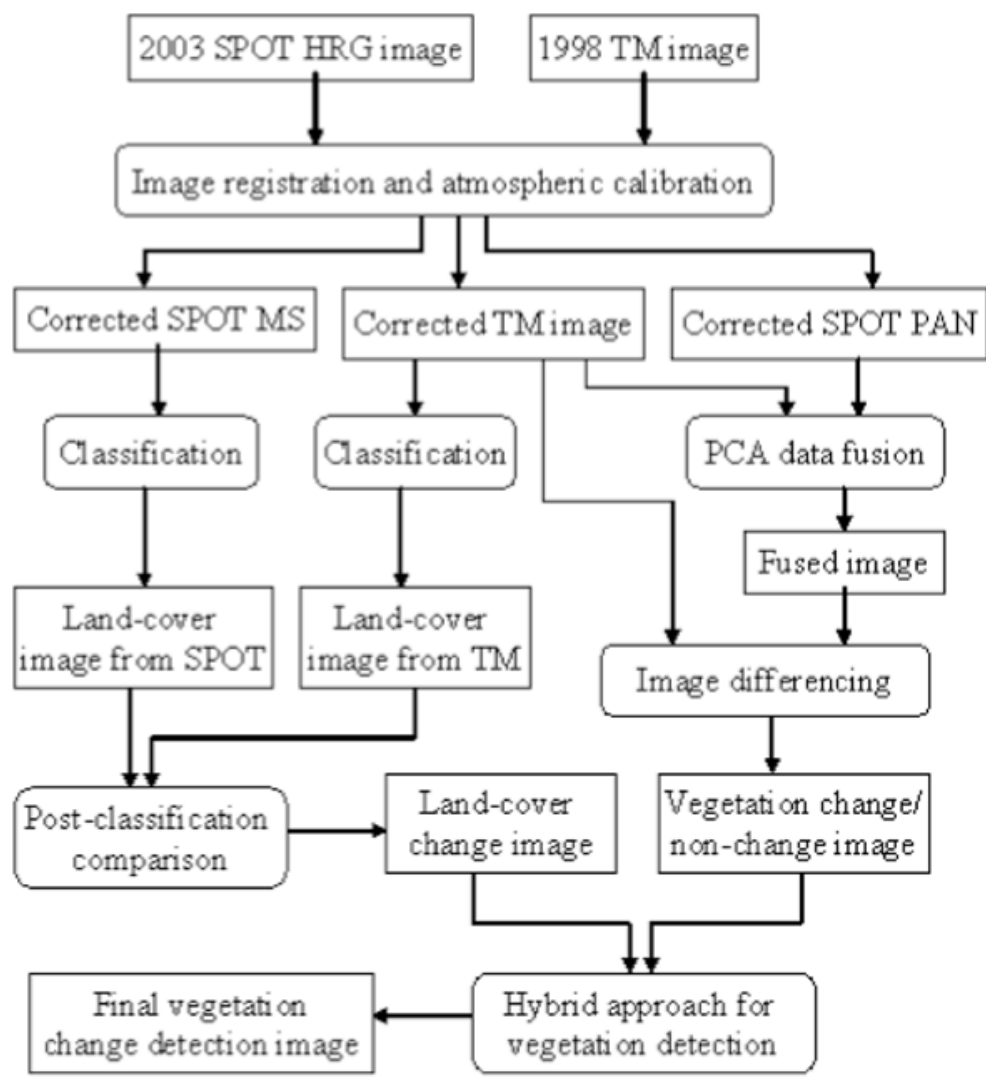

Figure 2.

Strategy for vegetation change detection based on Landsat TM and SPOT HRG data. (Note: MS: multispectral image, PAN: SPOT panchromatic image, and PCA: principal component analysis) 


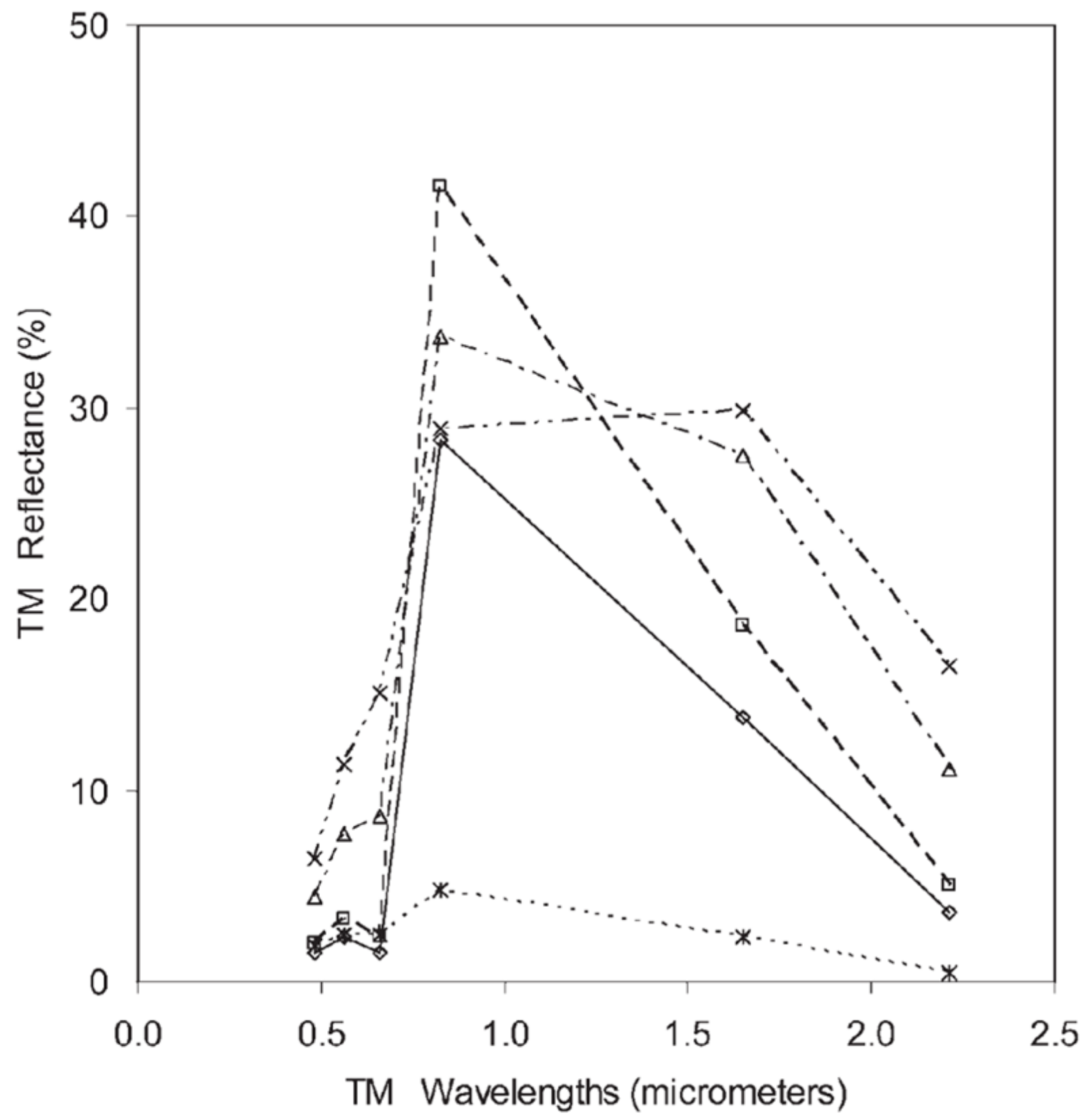

Figure 3.

Comparison of reflectance features (percentage) along TM wavelengths among major landcover types. 


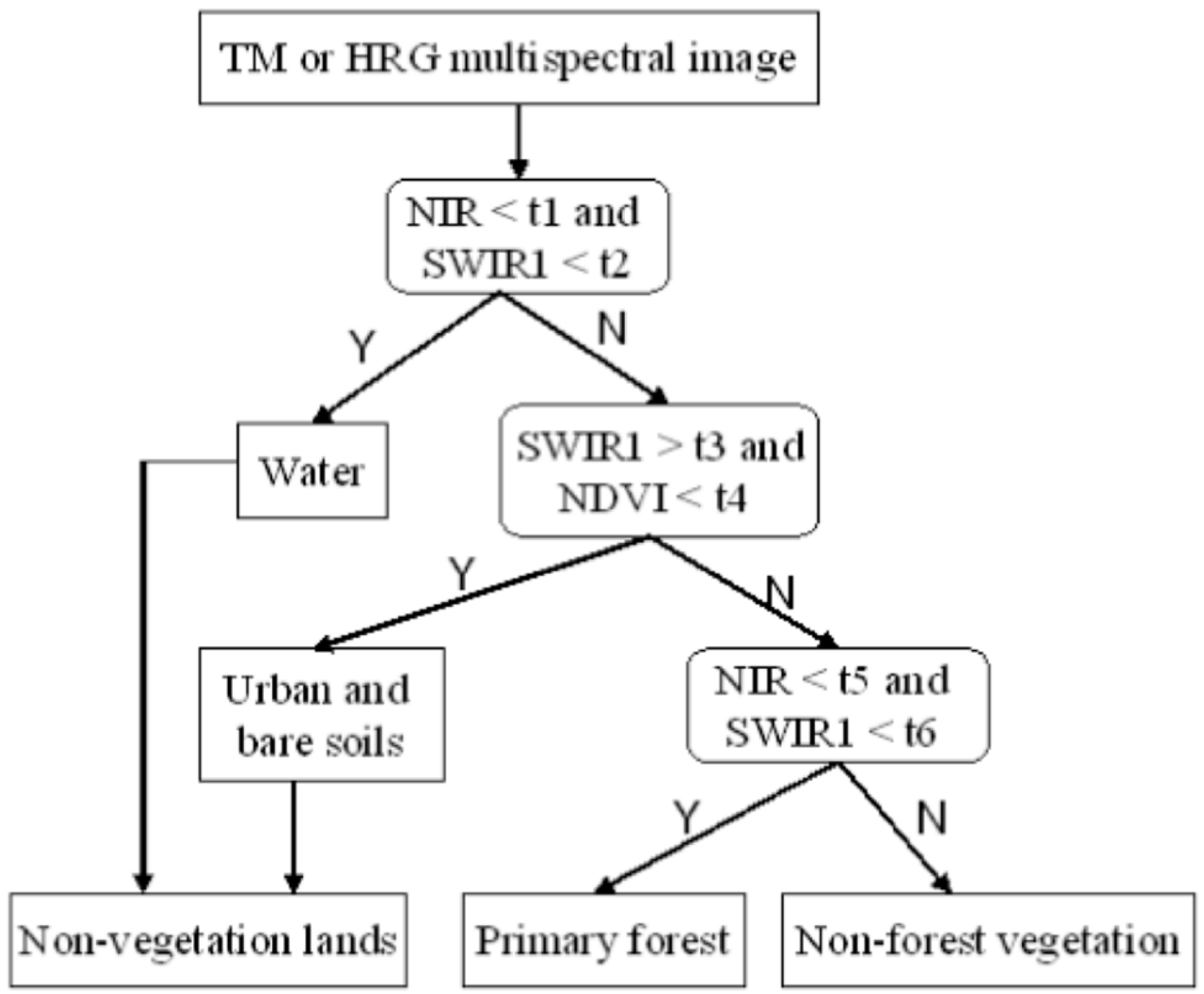

Figure 4.

A rule-based approach for land-cover classification. (Note: NIR represents near-infrared, and SWIR1 represents the shortwave infrared band, i.e., band 5 in TM data or band 4 in HRG data; NDVI represents the normalized difference vegetation index; and t 1 through t6 represent the thresholds developed from sample plots.) 


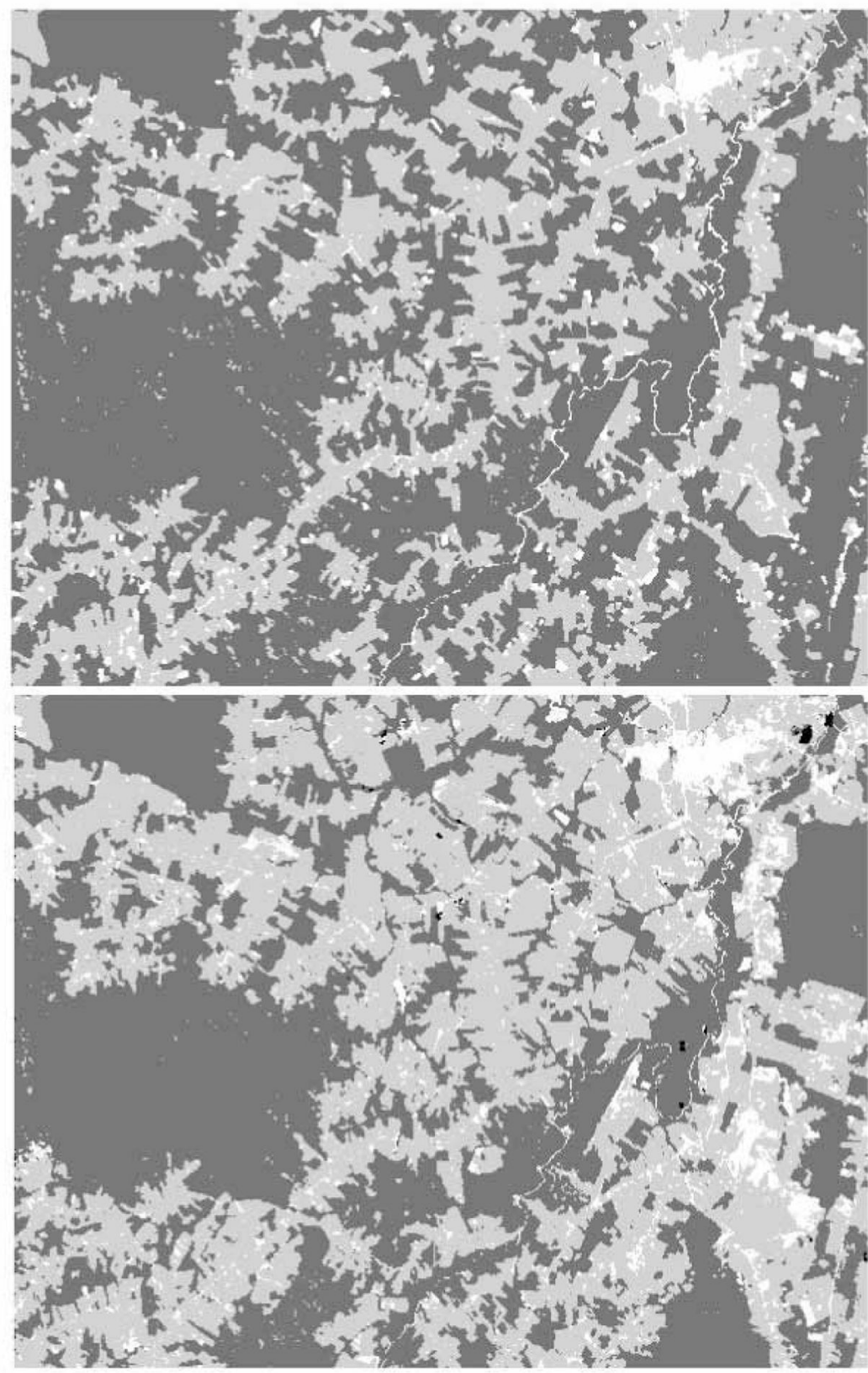

Figure 5.

Image classification results using a rule-based approach: (a) Landsat TM image in 1998, and (b) SPOT HRG image in 2003. 

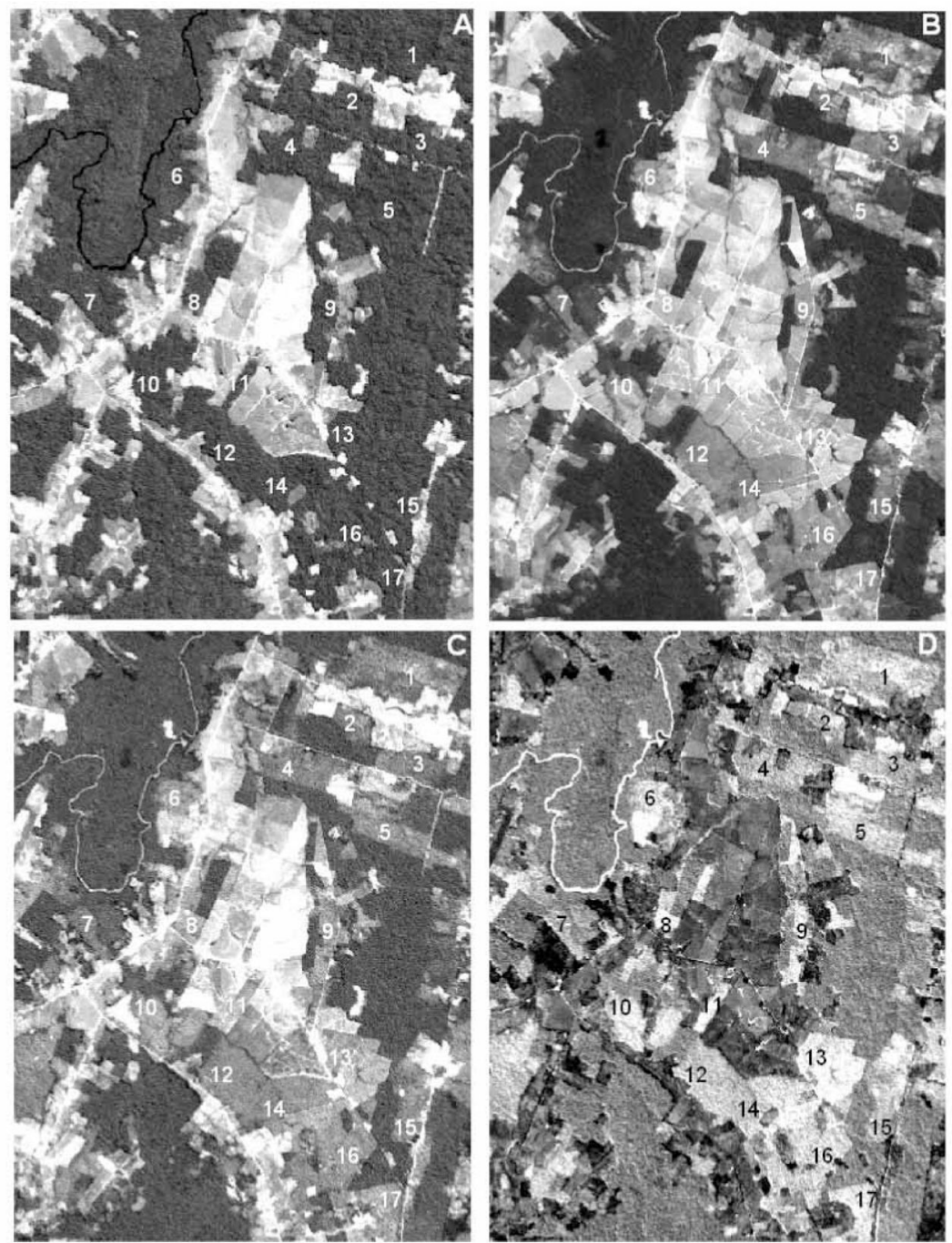

Figure 6.

A comparison of change detection results: (a) TM band 5 image in 1998, (b) SPOT panchromatic image in 2003, (c) band 5 image after data fusion, and (d) difference image between fused band 5 and original TM band 5 . 


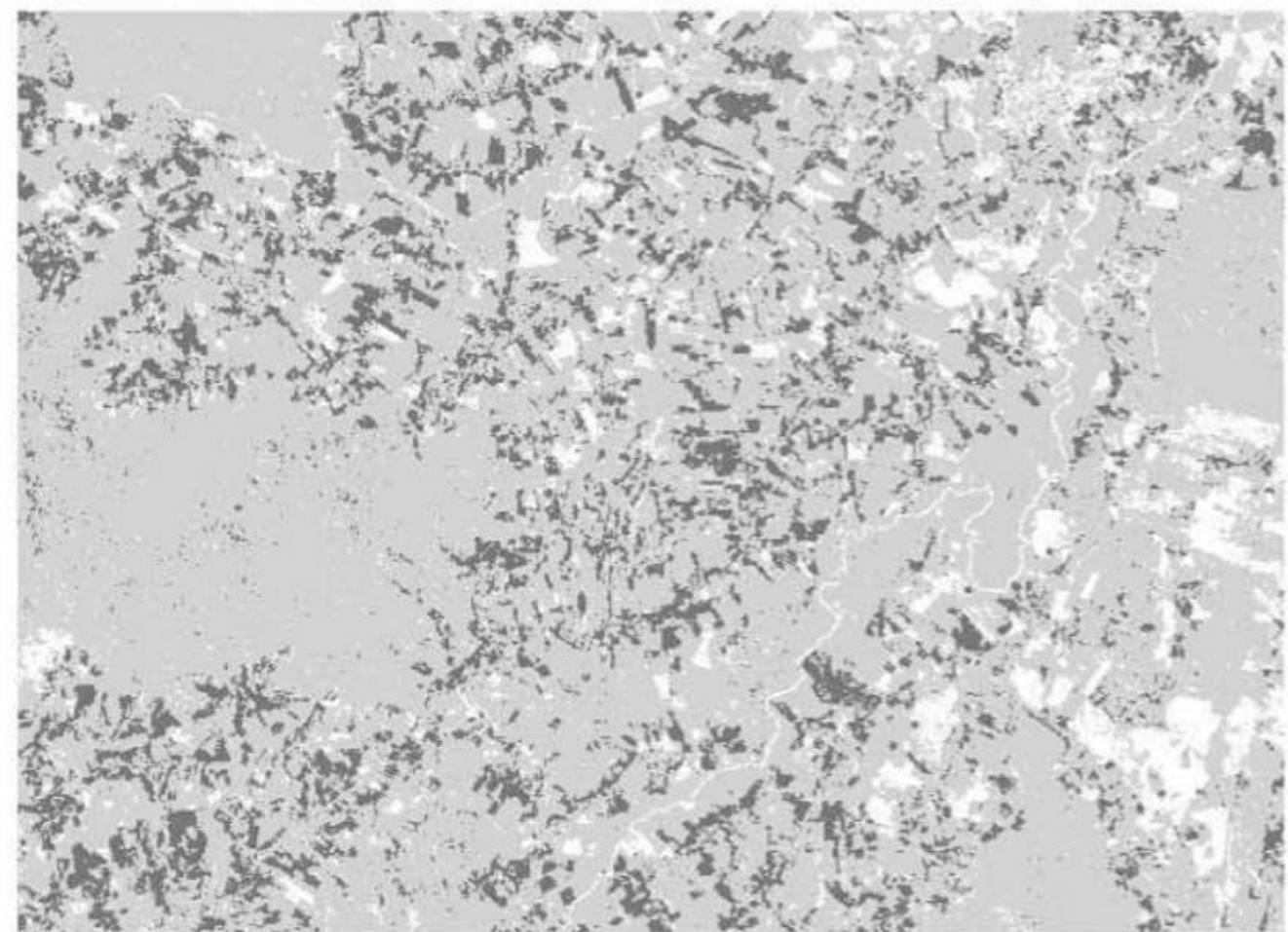

\section{Legend}
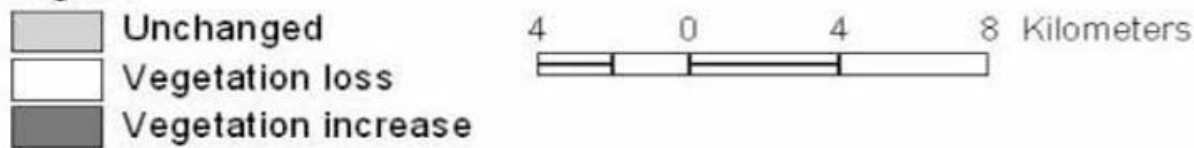

Figure 7.

Vegetation change/non-change detection image with majority rules on the image difference between data fused image and corresponding TM image. 


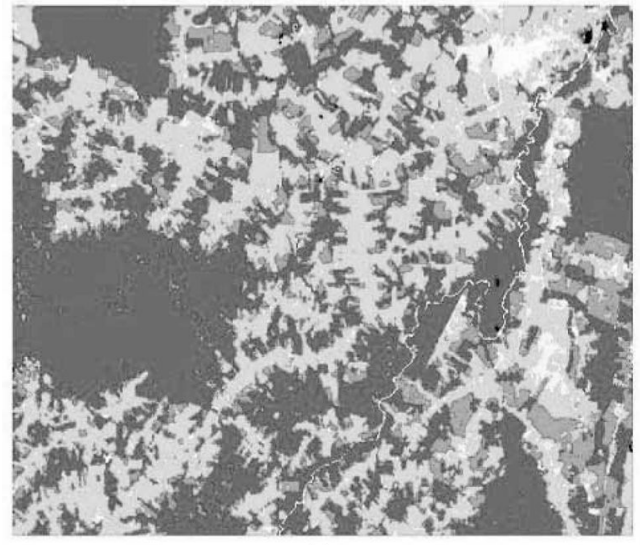

(a)

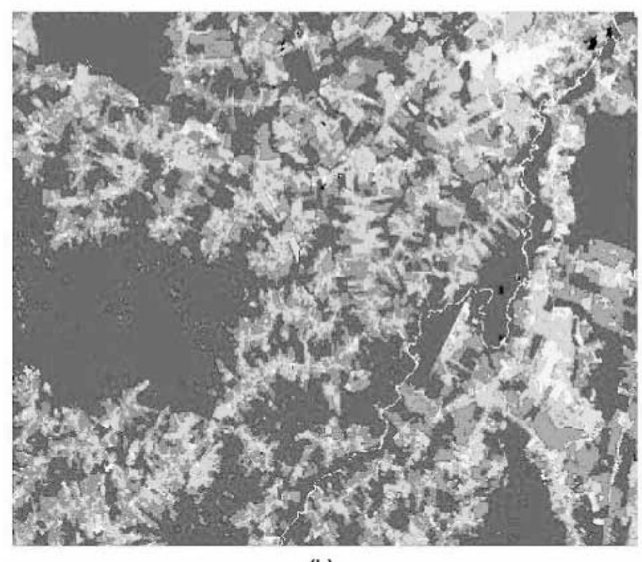

(b)
Change detection image

based on a post-classification

comparison approach

Legend

\begin{tabular}{l}
$\square$ Forest to NFV \\
\hline Forest to NVL
\end{tabular}

NFV to NVL

NVL to NFV

Less-dense to denser forest

Unchanged For est

Unchanged NFY

Unchanged NVL

Clouds \& Shades

NFVto NVL

NVL to NFV

Less-dense to denser forest

Unchanged For est

Unchanged NFV

Unchanged NVL

NFV loss

NFV gain

Clouds \& Shades

Figure 8.

Change detection image based on TM and HRG data: (a) post-classification comparison approach, and (b) the hybrid approach). (Note: NFV is non-forest vegetation, and NVL is nonvegetation land) A color version of this figure is available at the ASPRS website: www.asprs.org. 
Table 1

The Change Matrix Based on a Post-classification Comparison Approach

\begin{tabular}{|c|c|c|c|}
\hline & Forest & Non-forest Vegetation & Non-vegetation Land \\
\hline Forest & Unchanged forest & Forest to non- forest vegetation & Forest to non- vegetation land \\
\hline Non-forest vegetation & & Unchanged non- forest vegetation & $\begin{array}{l}\text { Non-forest vegetation to non- } \\
\text { vegetation land }\end{array}$ \\
\hline Non- vegetation land & & Bare soil to non- forest vegetation & Unchanged non- vegetation land \\
\hline
\end{tabular}

Notes: Forest means mature forest; non-forest vegetation includes different stages of successional vegetation, agroforestry, perennial agriculture (e.g., coffee, rubber, or cacao plantation), and pastures; non-vegetation land includes urban or residential areas, roads, water, and bare soil 


\section{Table 2}

Definition of Vegetation Change Trajectories

Change Trajectory Definition

Forest degradation

Forest improvement

Non-forest vegetation loss

Non-forest vegetation gain

Forest to non-forest vegetation

Forest to non-vegetation lands

Non-forest vegetation to non-vegetation lands

Non-vegetation land to non-forest vegetation
From mature dense forest in prior date to disturbed forest in late date

From less dense forest in prior date to denser forest in late date

From more mature vegetation in prior date to less mature vegetation in late date

From less mature vegetation in prior date to more mature vegetation in late date

From mature forest in prior date to non-forest vegetation types, such as pasture, perennial plantations, successional vegetation, in late date

From mature forest in prior date to non-vegetation land, such as bare soil, infrastructure, or water in late date

From non-forest vegetation, such as successional vegetation, agroforestry, or pasture, in prior date to non-vegetation land such as bare soil, infrastructure, or water in late date

From bare soil in prior date to non-forest vegetation, such as successionalvegetation, agroforestry, or pasture, in late date 